\title{
A LABORATORY SIMULATION OF PYROCLASTIC FLOWS DOWN SLOPES
}

\author{
HERBERT E. HUPPERT ${ }^{1}$, J. STEWART TURNER ${ }^{2}$, STEVEN N. CAREY ${ }^{3}$, \\ R. STEPHEN J. SPARKS ${ }^{4}$ and MARK A. HALLWORTH ${ }^{1}$
}

${ }^{1}$ Department of Applied Mathematics and Theoretical Physics, University of Cambridge, Silver Street, Cambridge CB3 $9 E \mathrm{~W}$, England

${ }^{2}$ Research School of Earth Sciences, Australian National University, Canberra, A.C.T. 2601, Australia

${ }^{3}$ Graduate School of Oceanography, University of Rhode Island. Kingston, RI 02881 , U.S.A.

${ }^{4}$ Department of Earth Sciences, Downing Site, University of Cambridge, Cambridge CB2 $3 E Q$, England

(Received October 29, 1985; revised and accepted June 16, 1986)

\section{ABSTRACT}

Huppert, H.E., Turner, J.S., Carey, S.N., Sparks, R.S.J. and Hallworth, M.A. 19886. A laboratory simulation of pyroclastic flows down slopes. $J$. Volcanol. Geotherm. Res., 30 : 179-199.

Laboratory experiments are described which explore the dynamical consequences of buoyant convective upflow observed above hot pyroclastic flows. In nature, the convection is produced by the hot ash particles exchanging heat with air mixed into the front and top of the pyroclastic flow. This effect on the buoyancy due to the mixing of air and ash has been modelled in the laboratory using mixtures of methanol and ethylene glycol (MEG), which have a nonlinear density behaviour when mixed with water. Intermediate mixtures of these fluids can be denser than either initial component, and so the laboratory experiments were inverted models of the natural situation. We studied MEG flowing up under a sloping roof in a tank filled with water. The experiments were performed both in a narrow channel and on a laterally unconfined slope. The flow patterns were also compared with those of conventional gravity currents formed using fresh and salt water. The presence of the region of reversed buoyancy outside the layer flowing along the slope had two significant effects. First, it periodically protected the flow from direct mixing with the environment, resulting in pulses of relatively undiluted fluid moving out intermittently ahead of the main flow. Second, it produced a lateral inflow towards the axis of the current which kept the current confined to a narrow tongue, even on a wide slope.

In pyroclastic flows the basal avalanche portion has a much larger density contrast with its surroundings than the laboratory flows. Calculations show that mixing of air into the dense part of a pyroclastic flow cannot generate a mixture that is buoyant in the atmosphere. However, the overlying dilute ash cloud can behave as a gravity current comparable in density contrast to the laboratory flows and can become buoyant, depending on the temperature and ash content. In the August 7 th pyroclastic flow of Mount St. Helens, Hoblitt (1986) describes pulsations in the flow front, which are reminiscent of those observed in the experiments. As proposed by Hoblitt, the pulsations are caused by the ash cloud accelerating away from the front of the dense avalanche as a density 
current. The ash cloud then mixes with more air, becomes buoyant and lifts off the ground, allowing the avalanche to catch up with and move ahead of the cloud. The pulsing behaviour at the fronts of pyroclastic flows could account for the occurrence of cross-bedded layer 1 deposits which occur beneath layer 2 deposits in many sequences.

\section{INTRODUCTION}

Observations of pyroclastic flows and their deposits suggest that they consist of a dense underflow and an overlying turbulent cloud. The underflow is generally thought of as having a high concentration of particles and in which only limited grain size and density sorting can occur (Sparks, 1976). The overlying turbulent cloud is known to be dilute and contain only fine-grained ash. Within the cloud, buoyancy effects may be important because mixtures of hot ash and air can be less dense than the cold air that overlies the flow. Theoretical and experimental work suggests that the cloud is formed by mixing of air into the flow head (Wilson and Walker, 1982), by elutriation of fine ash by gas fluidisation from within the dense underflow (Sparks, 1976; Wilson, 1980) and by the development of a turbulent boundary layer across the upper surface of the dense underflow (Denlinger, 1986).

Pyroclastic flows are now recognised as a class of gravity current (Wilson, 1980; Simpson, 1982). A number of the geological features of their deposits and the behaviour of the flows themselves indicate that mixing of air into the flow head is important. The application of concepts developed from experimental and theoretical studies of simple gravity currents to pyroclastic flows has provided some insight into the flow dynamics. However, there are at least two major differences between pyroclastic flows and simple laboratory gravity currents. First, pyroclastic flows owe their excess density to solid particles which can segregate within and sediment out from the flow. The density contrast between pyroclastic flows and their environment is much larger than that of typical laboratory gravity currents. However, the overlying dilute cloud must of necessity have only a small contrast with surrounding air, comparable with those of laboratory density currents. Second, the flows mix with relatively cold atmospheric air which will expand greatly as it is heated by the hot particles. There have been a number of speculations on what influence these complicating factors might have on the dynamics of flows (Sparks, 1976; Wilson, 1980; Wilson and Walker, 1982), but there has been little experimental work on the new effects that might occur, with the exception of a gas fluidisation. Wilson (1980, 1984) carried out a systematic experimental study of the effects that gas expansion and fluidisation would have on pyroclastic flow material and showed that uniform fluidisation of this material is impossible. Wilson's studies indicated that many sedimentary structures in pyroclastic flow deposits are a consequence of uneven fluidisation of the original pyroclastic flow due to ingestion of air into the flow front (Wilson, 1984). 
In this paper we present a series of experiments designed to investigate the influence of a buoyant upper cloud on the dynamics of a gravity current. In nature, mixing of cold air and hot ash particles in the dense underflow and within the overlying cloud can create buoyant regions in the flow because of the heat transfer from the ash particles to the surrounding air. This is an example of a system in which the density of the resulting mixture is considerably lower than either of the two inputs - cold air and hot particles. This nonlinear density effect on mixing can be simulated by the mixing of certain fluids. We have formed laboratory gravity currents which generate a buoyant cloud by using mixtures of methanol and ethylene glycol as the input fluid for the gravity currents. The input fluid propagated into fresh water and mixed nonlinearly with it. The purpose of the experiments was to compare the behaviour of gravity currents which generate an overriding byoyant cloud with simple gravity currents. We describe in the final section the extent to which these experiments help in understanding the behaviour of pyroclastic flows and the geological features of their deposits.

\section{EXPERIMENTAL TECHNIQUES}

Mixtures of methanol and ethylene glycol (MEG) can be made with densities between $0.792 \mathrm{~g} \mathrm{~cm}^{-3}$ (pure methanol) and $1.126 \mathrm{~g} \mathrm{~cm}^{-3}$ (pure ethylene glycol). When MEG is mixed with water, the density of the resultant can be greater than that of either of the ingredients, as shown quantitatively in Fig. 1. This nonlinear mixing generates a product whose density contrast is of the opposite sign to that of the less dense buoyant cloud produced above a pyroclastic flow. However, no simple fluid analogue which results in a less dense mixture is known to us, so we used the simple device of allowing the MEG current to flow up underneath a sloping roof. It is then easy to invert all photographs of an experiment to depict a current flowing

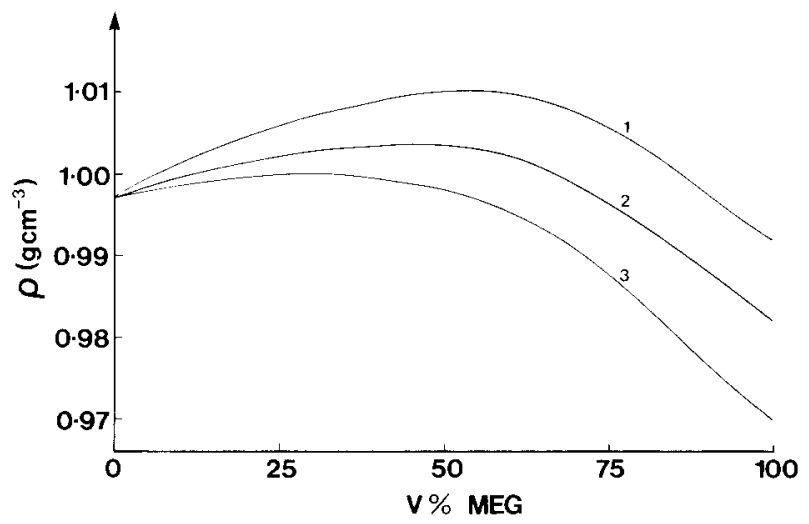

Fig. 1. The density of a mixture of methanol ethylene glycol (MEG) and water as a function of the volume percentage of MEG: $1=54.5 \%$ by volume of methanol in the undiluted MEG; $2=51.5 \%$ by volume of methanol; and $3=48.0 \%$ by volume of methanol. 
down a slope which on mixing with the environment produces motion of a less dense fluid above the current, as in nature. The dynamics of the two situations are, of course, identical.

There only remains the question of how to describe the laboratory flows. We decided in this paper both to print the photographs and to explain the processes from an inverted view, and thus be consistent with the naturally occurring phenomena.

The use of MEG-water and related mixtures has been described previously by Turner and Yang (1963) and Turner (1966), who used them to simulate evaporation in convective clouds in the atmosphere, and by Turner and Gustafson (1978), who suggested that nonlinear mixing phenomena may play a role in determining the products of hot, salty effluents from the sea floor.

For our purposes the MEG-water system nicely simulates the effects of the density decrease of the entrained air due to heat loss from the small ash particles. Our study does not simulate, however, the segregation and sedimentation of the material within and from the pyroclastic flow.

We used two different pieces of apparatus in our experiments, as sketched in Fig. 2. In the first, MEG was pumped along a $30 \mathrm{~cm}$ horizontal pipe and then released onto the slope through a nozzle of internal diameter $7 \mathrm{~mm}$ at the end, as despicted in Fig. 3a*. The slope angle $\theta$ was preset at either 15 , 30 or $45^{\circ}$ and the length, $L$, of the slope was approximately $60 \mathrm{~cm}$. The width of the slope $D$ was $7.5 \mathrm{~cm}$ and it fitted snugly into a Perspex tank of comparable width. The flow was viewed by shadowgraph across the tank and by direct observation onto the slope. In all experiments the fluids were at room temperature $\left(\approx 18^{\circ} \mathrm{C}\right)$.

While much was ascertained from experiments in this apparatus, we were concerned about the restricting influence of the confining walls. We thus performed some experiments in a second, much wider container, for which $L \approx 60 \mathrm{~cm}$ and $D \approx 60 \mathrm{~cm}$. In this apparatus we also experimented with

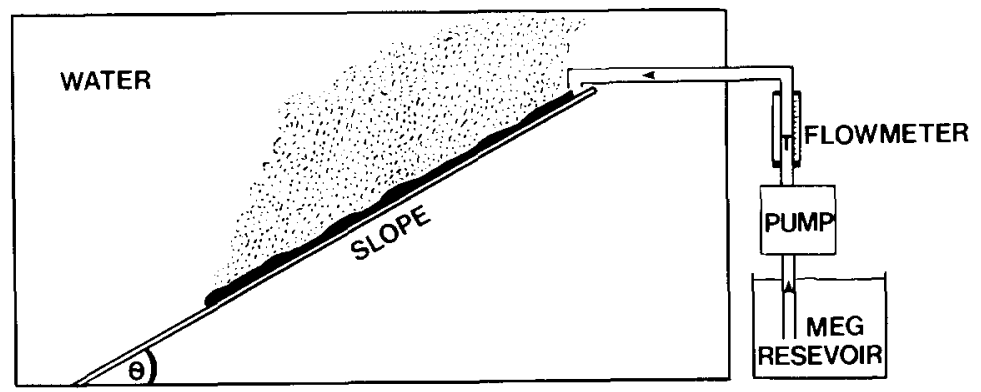

Fig. 2. An elevational sketch of the experimental set-up. (Recall that this sketch must be inverted to view the apparatus as seen in the laboratory.)

* Recall that this figure and all descriptions are inversions of what actually occurred. 


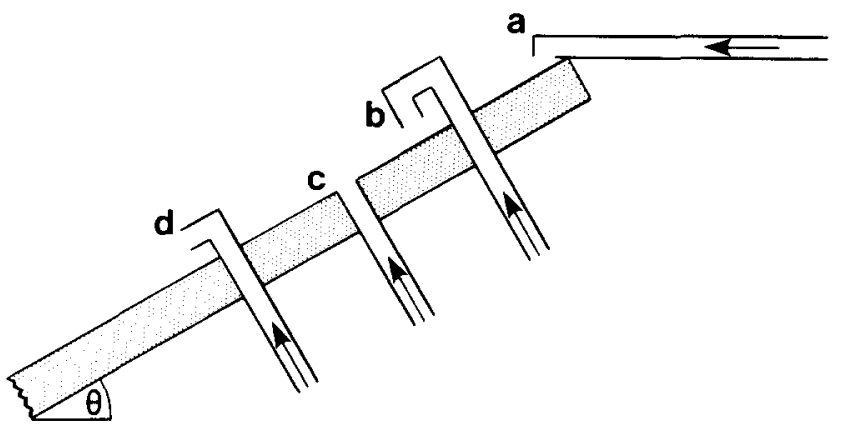

Fig. 3. The four different nozzle designs used in the experiments. Nozzle $a$ was used in the smaller apparatus; nozzles $b$ (on-slope), $c$ (off-slope) and $d$ (along-slope) in the larger apparatus.

three different nozzles in order to investigate the effect of input conditions. One nozzle directed the flow on slope, one off slope and the final one along slope, as sketched in Fig. $3 \mathrm{~b}-\mathrm{d}$. We found the along slope release to be the most satisfactory, and will present below the detailed results using this configuration. Overall, results from the second apparatus were qualitively the same as those from the first, and indicated that the effects we describe are independent of the finite size of the laboratory containers.

In the next section we briefly describe the effects observed in a simple gravity current. This acts as a background with which to compare the new effects due to nonlinear mixing.

\section{SIMPLE GRAVITY CURRENTS}

To contrast with the MEG experiments, we performed several experiments on simple gravity currents. In these experiments, fresh water flowed initially along a slope in a salt-water environment. The initial density difference between the current and its environment, $\Delta \rho$, was approximately $10^{-2} \mathrm{~g}$ $\mathrm{cm}^{-3}$. The outputs from the nozzle, $Q$, ranged between 3 and $6 \mathrm{~cm}^{3} \mathrm{~s}^{-1}$, and thus the input Reynolds numbers based on the nozzle radius $(0.35 \mathrm{~cm})$ ranged between $10^{3}$ and $2 \times 10^{3}$. Even the minimum value is sufficient to make the flow turbulent.

In the second, larger, apparatus the currents spread out across the slope as they flowed along it, in such a way that the lateral edge of the current formed a straight-sided cone, as depicted in the plan view of Fig. 4a. Just behind the head of the current, and for some distance along the top of it, ambient fluid was entrained into the current, thereby slightly decreasing the density contrast between current and environment. At all times the current remained attached to the slope, as is evident in the elevation shown in Fig. $4 \mathrm{~b}$. Although the flow in the input nozzle was kept steady, the flow down the slope was not as steady in either time or space. Instabilities developed which led to variations in the thickness of the current, as seen by the variations of optical density in Fig. $4 a$.

The head of the current propagated along the slope at an approximately 


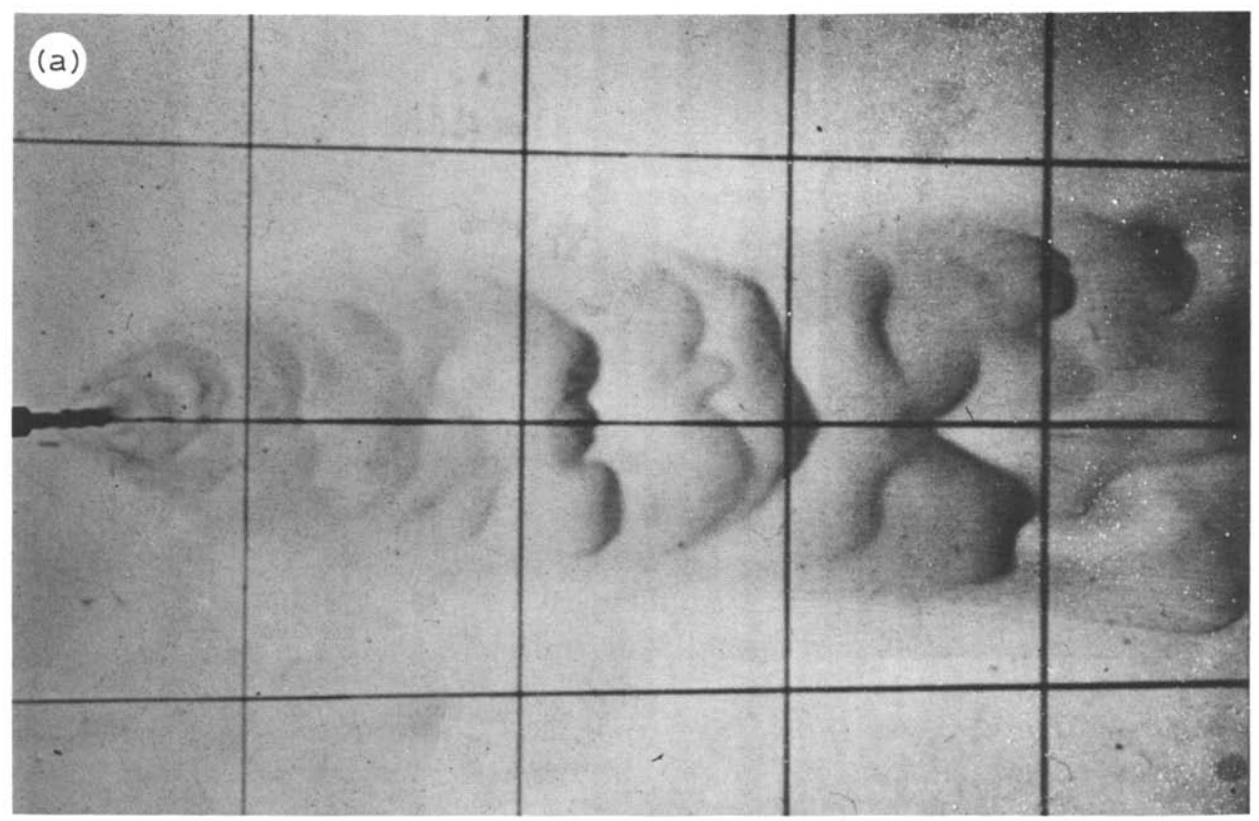

(b)

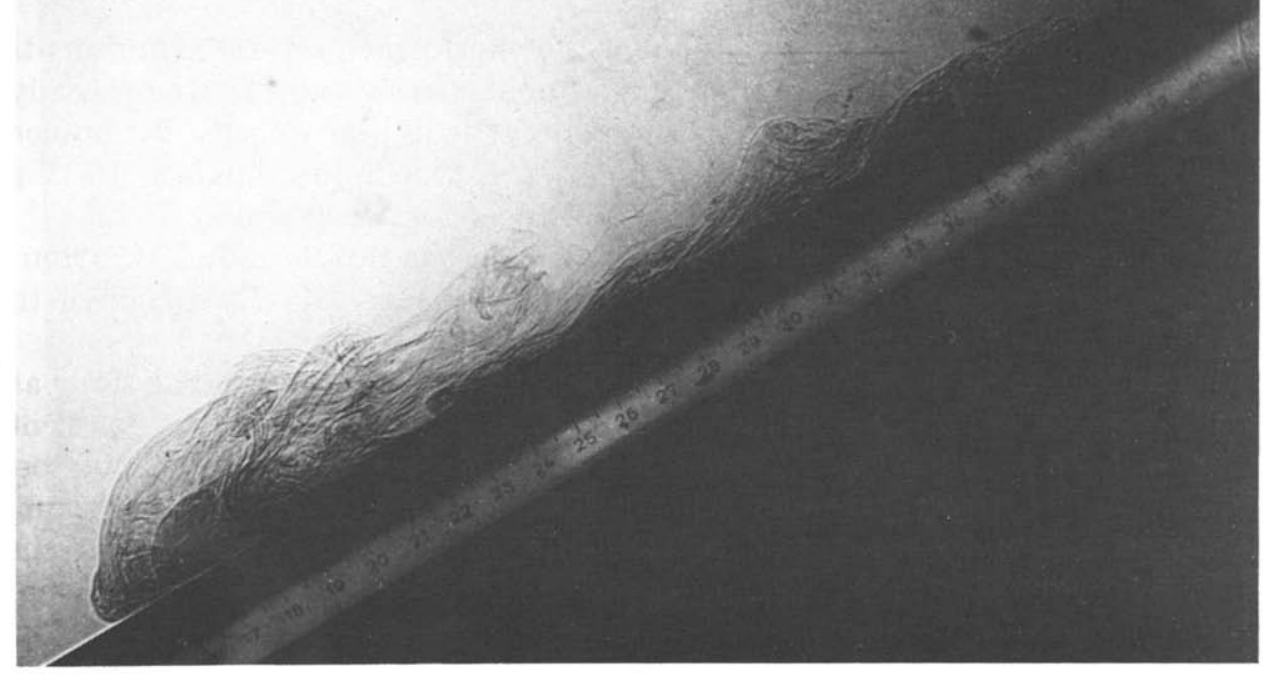

Fig. 4. Simple gravity currents along a slope. (a). Plan, $Q=1.71 \mathrm{~cm}^{3} \mathrm{~s}^{-1}, \Delta \rho=0.007 \mathrm{~g}$ $\mathrm{cm}^{-3}$ in the larger apparatus (with nozzle $d$ ) $45 \mathrm{~s}$ after release. (b). Elevation, $Q=3.1 \mathrm{~cm}^{3}$ $\mathrm{s}^{-1}, \Delta \rho=0.0006 \mathrm{~g} \mathrm{~cm}^{-3}$ in the smaller apparatus (with nozzle $a$ ) $15 \mathrm{~s}$ after release. 
constant speed which was dependent on the flow rate $Q$, the angle of the slope $\theta$, and the reduced gravity $g^{\prime}=g \Delta \rho / \rho$, where $g$ is the acceleration due to gravity and $\rho \approx 1.0 \mathrm{~g} \mathrm{~cm}^{-3}$, which is the initial density of the input fluid. The cone angle was also dependent on $Q, \theta$ and $g^{\prime}$.

There exists a theoretical description of a two-dimensional gravity current on a slope which has been intensively compared with laboratory experiments (Britter and Linden, 1980). The different situation considered here, in which the fluid issues from a point source, has not been analysed. A prediction of the velocity of the head and the cone angle still needs to be developed.

In the smaller apparatus, the current flowed along the slope and spread across it until it encountered the walls. Thereafter it propagated as a twodimensional current with little variation across the slope. At no time, however, did any part of the current become detached from the slope.

\section{GRAVITY CURRENTS WITH BUOYANT CLOUDS}

Having described the behaviour of normal gravity currents, we now contrast the new phenomena which were exhibited in our experiments with MEG. We carried out experiments with initial density differences between input fluid and water of $0.006,0.016$ and $0.028 \mathrm{~g} \mathrm{~cm}^{-3}$ (curves 1,2 and 3 respectively of Fig. 1) which are comparable to those used for the normal gravity currents. The flow rates were also similar. Thus these flows were also turbulent, at least initially. Some of the lower flow rates seemed to produce a transitional flow regime, and we comment on this further below.

A large number of different phenomena were observed. We shall first describe the general flow properties and then go on to describe the special aspects associated with high values of $Q$.

As the current propagated along the slope, extensive mixing with the environmental fluid occured at the head of the current and behind it to form a mix ture which detached from the slope and rose through the environmental fluid. This is depicted in Fig. 5a. The vertical motion to each side of the current drove a large-scale convective cell with axes along the slope, as sketched in Fig. 5b. The result of this convective motion was to confine the basal current to a rather narrow band, as seen in Fig. 5c, which contrasts markedly with the lateral expansion of the normal gravity current (Fig. 4b).

Except possibly for the very slowest flows, the front of the flow was quite unsteady and the current exhibited strong spatial and temporal variations along the slope (Fig. 6). The mixing with the environment of the input fluid which flowed along the slope often formed a 'protective cover' over the undiluted MEG at the head and further mixing was momentarily delayed. This allowed dense unmixed MEG from behind the flow front to flow out ahead to form a bulbous clump of fluid. Such an event is evident in Fig. 5 d. The clumps of dense fluid eventually mixed with ambient fluid and decelerated as the mixture lifted off the slope. The flow front sometimes even 
retreated slightly upslope as lift-off took place. The unsteady motions at the flow head are illustrated by data in Fig. 6 . The overlying buoyant cloud often consisted of discrete pulses or protuberances of buoyant fluid, each of which originated as a pulse of dense fluid.
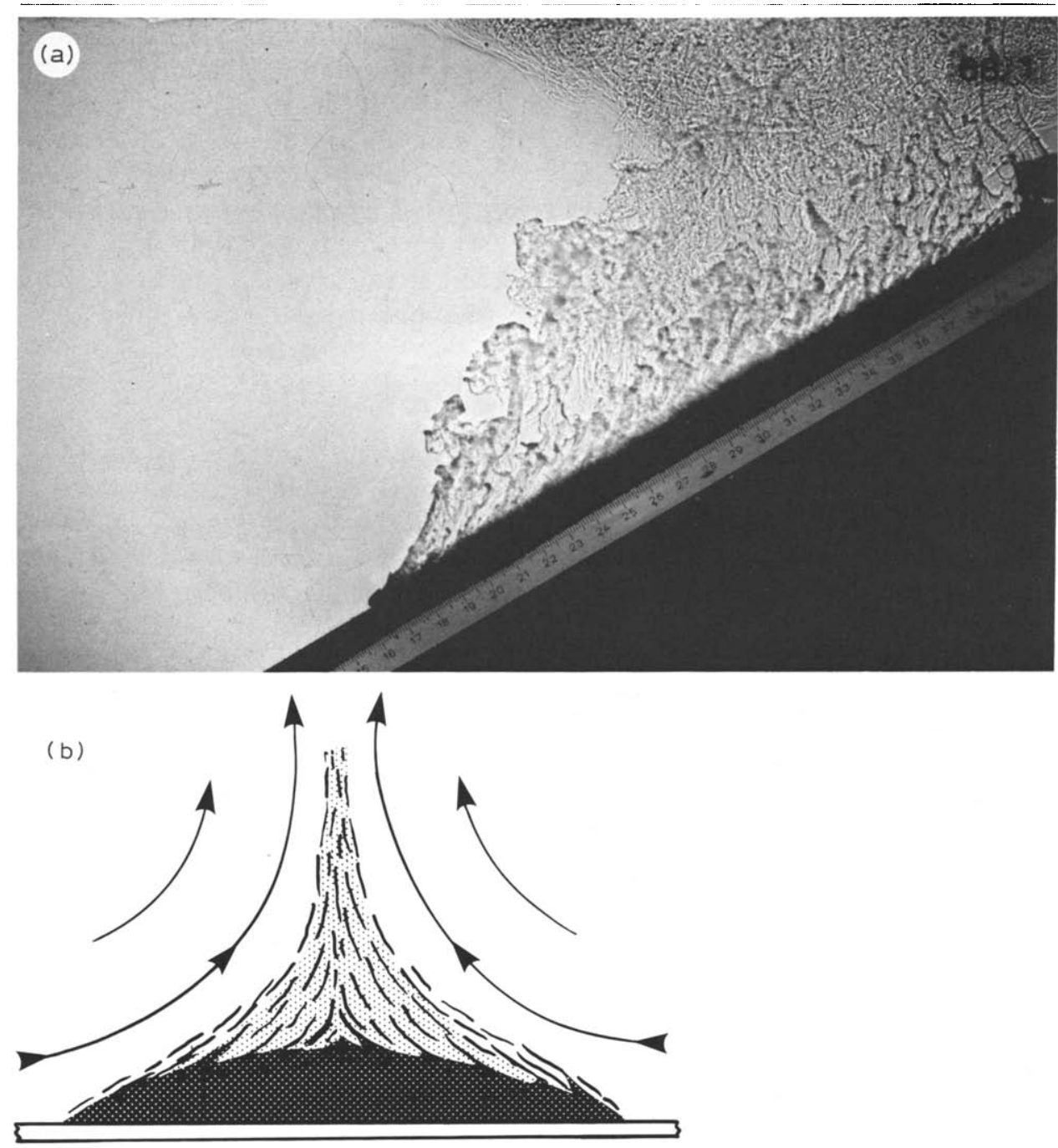

Fig. 5. Gravity currents with buoyant clouds along a slope. All the experiments pictured here used MEG of composition 1 as shown in Fig. 1.

(a) Elevation, $Q=0.775 \mathrm{~cm}^{3} \mathrm{~s}^{-1}$ in the small apparatus (with nozzle $a$ ) $45 \mathrm{~s}$ after release. Note the bulbous head at the front of the flow and the rising plumes all the way behind it. (b) Sketch of the motion in cross-section. The main current (dense stipple) mixes to produce a buoyant plume (light stipple) which induces a mean flow in the outer environment. This flow laterally confiness the main current. 

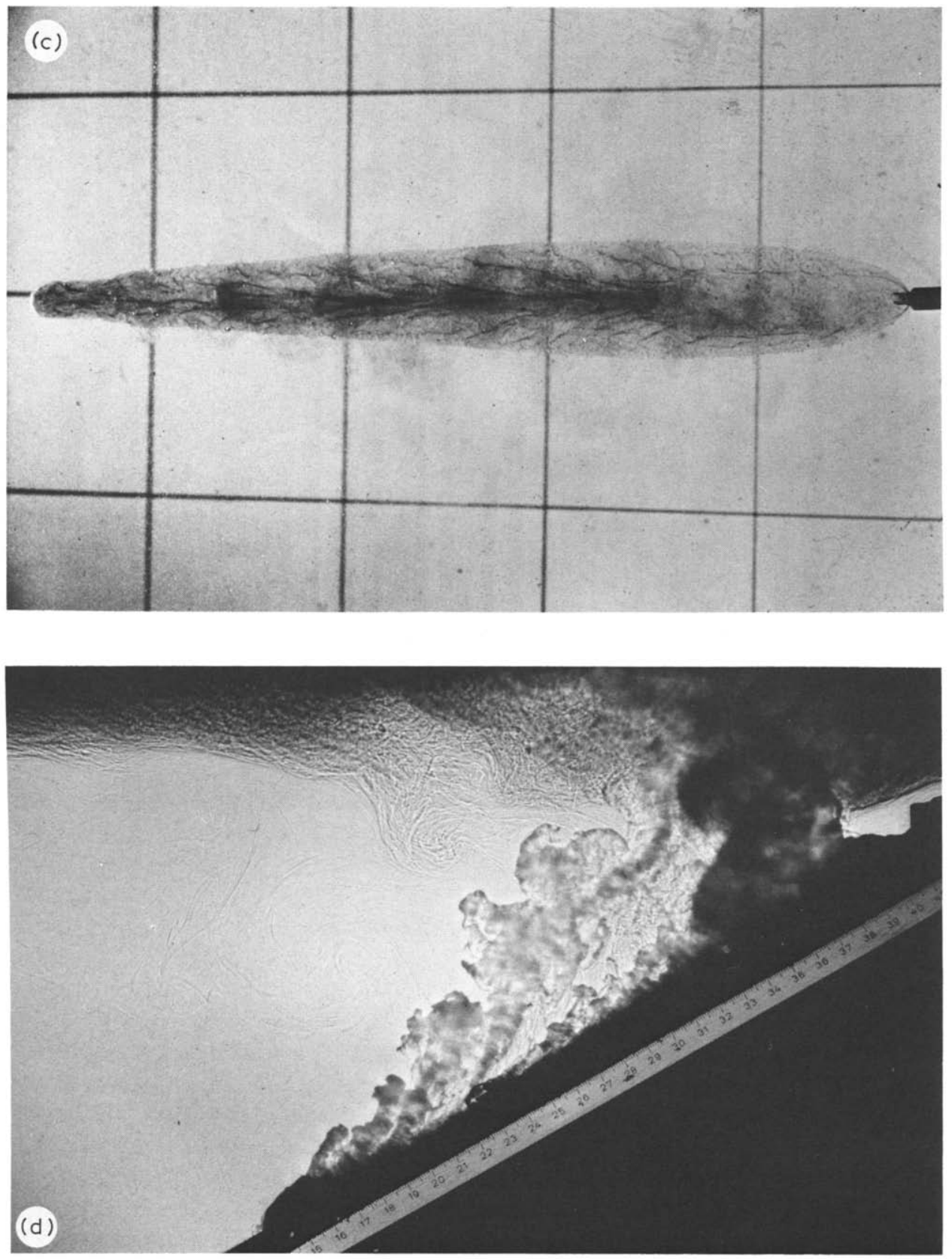

Fig. 5. (c) Plan, $Q=0.50 \mathrm{~cm}^{3} \mathrm{~s}^{-1}$ in the larger apparatus (with nozzle $d$ ) $90 \mathrm{~s}$ after release. Note the confinement of the current, the grey clouds of buoyant material as seen from below the current and the fine-grained streakiness, similar in form to the veins of a leaf. (d) Elevation, $Q=5.7 \mathrm{~cm}^{3} \mathrm{~s}^{-1}$ in the smaller apparatus (with nozzle $a$ ) $40 \mathrm{~s}$ after release. Note the bulbous front, the rising plumes and second clump of dense fluid between approximately 22 and $23 \mathrm{~cm}$. 

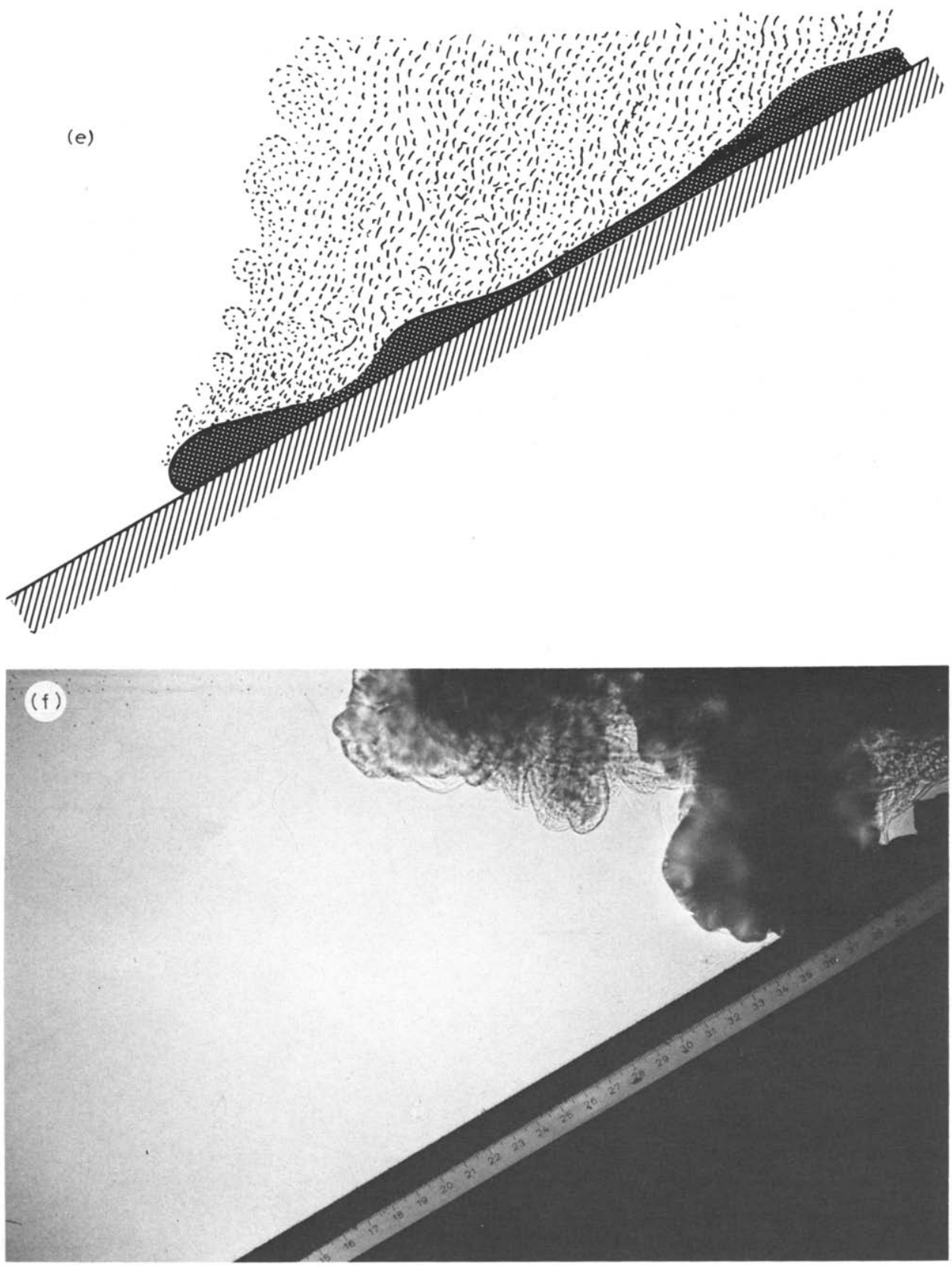

Fig. 5. (e) An elevational sketch showing clearly the important aspects of the flow. Note the bulbous front, the following clumps of unmixed fluid which have surged down the slope and the rising plumes.

(f) Elevation of a total lift-off, $Q=7.8 \mathrm{~cm}^{3} \mathrm{~s}^{-1}$ in the smaller apparatus (with nozzle $a$ ) 12 s after release. Note that the MEG has flowed only a short distance down the slope before all of it has mixed with the surroundings to form a buoyant mixture which detaches from the slope. 

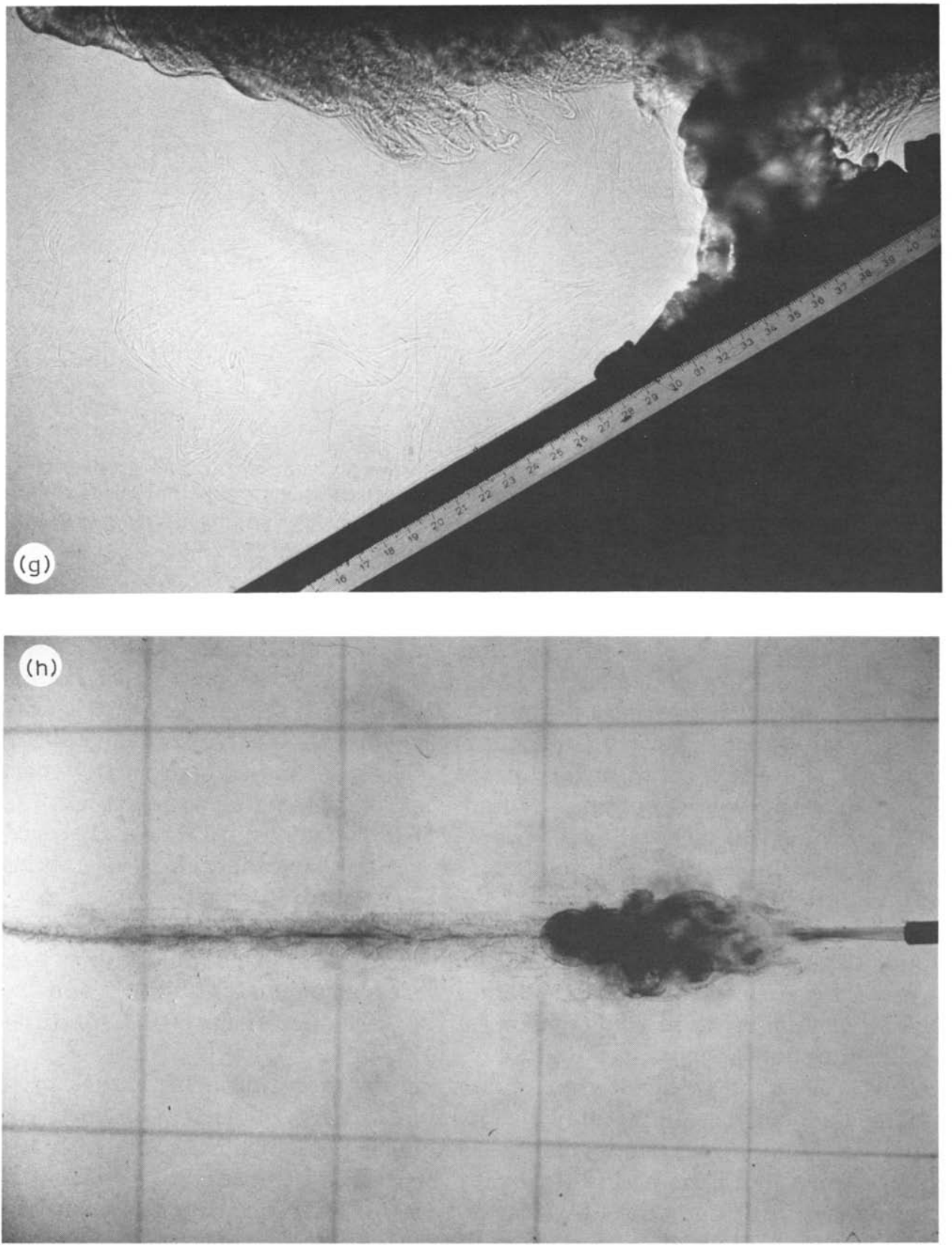

Fig. 5. (g) Elevation of a flow transitional to lift-off, $Q=6.4 \mathrm{~cm}^{3} \mathrm{~s}^{-1}$ in the smaller apparatus (with nozzle $a$ ) $20 \mathrm{~s}$ after release. Note that most of the MEG has mixed with the surroundings to form a plume but a small amount continues to flow down the slope. (h) Plan of a flow transitional to lift-off, $Q=3.1 \mathrm{~cm}^{3} \mathrm{~s}^{-1}$ in the larger apparatus (with nozzle d) $135 \mathrm{~s}$ after release. Note the rapid efflux from the nozzle, the thick buoyant plume and the relatively thin, wispy current that continues to flow along the slope. 


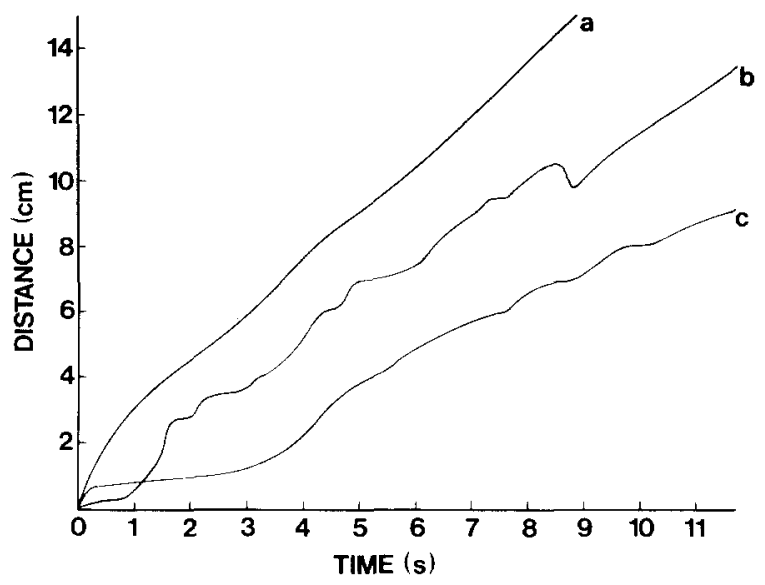

Fig. 6. Distance versus time plots for two nonlinear gravity currents and one simple gravity current. Note the contrast between the smooth propagation of the simple gravity current (upper curve a) with the unsteady propagation of the nonlinear currents (lower two curves $b$ and $c$ ). The flow front actually retreats slightly upslope at times of vigorous buoyant rise from the bulbous head.

Piles of dense fluid were often periodically accumulated along the current. This created a wavy appearance to the flow, as is also evident in Fig. 5d. A sketch of an ideal flow, showing most of these features, makes up Fig. 5e. The spatial variation caused the head of the current to surge and the motion along the slope was often rather uneven*. The motion in the underflow part of the current was sometimes reminiscent of kinematic waves (Lighthill, 1979). From plan views (Fig. 5c) is was also evident that a repeated streakiness along the slope was developed, presumably by the action of mixing with external fluid.

The exact details of the flow depend quite sensitively on the input conditions, namely the initial Reynolds number of the current and the nozzle shape. Of course the quantitative details were also dependent upon $\theta$ and the degree of nonlinear mixing, which can be varied by using MEG mixtures of different components (see Fig. 1).

Low values of $Q$ resulted in almost laminar motion with rather little mixing and convection. It may be possible to have currents with very low Reynolds number which would mix exceedingly little, if at all, with the environment. With increasing flow rate the degree of unsteadiness and mixing increased until a situation we refer to as 'lift off' occurred. In this situation, during its flow along the slope for only a few centimetres, the current had mixed sufficiently with the environment that all the fluid was now

* This observation was clearly visible when watching an experiment and was well reproduced in the movie sequences we made of the experiments. Unfortunately, it is impossible to show in the still photographs displayed in this paper. 
buoyant and totally separated from the surface (see Fig. 5f). For a very small range of flow rates just at the transition from a turbulent gravity current to a turbulent plume, a thin attached current could still be seen ahead of the lift-off point. This can be detected in Figs. $5 \mathrm{~g}$ and $\mathrm{h}$. In some experiments in the smaller apparatus very narrow $(1-2 \mathrm{~mm})$ fingers of dense MEG formed and moved beyond the bulbous flow front. As many as four fingers were sometimes observed. However, it was difficult to reproduce this behaviour consistently and we are uncertain of its significance.

The three different nozzles used in the larger apparatus resulted in somewhat different flow fields, at least near the nozzles. The on-slope release (Fig. $3 \mathrm{~b}$ ) required the input fluid to turn two sharp bends just before release. This caused a great deal of vorticity and secondary circulation (Prandtl, 1954) and resulted in a significant part of the current being initiated across the slope and hence two branches developed (see Fig. 7a). These eventually merged further along the slope (Fig. $7 \mathrm{~b}$ ).

The off-slope release (Fig. 3c) allowed the momentum of the input to carry it off the slope and facilitated the mixing. For slowish flows, the fluid, because of its density, would re-attach itself to the slope and continue to flow along it. However, faster flows resulted in the input mixing so vigorously with the environment that only a plume formed and no current was generated.

The along-slope release (Fig. 3d) was the most satisfactory, with its output not being dominated by secondary circulation and the resulting current being able, at least initially, to flow along the slope.

The sensitivity of the motion observed in the experiments to the details of the output suggest that the exact configuration of a volcanic vent may play an important role in determining the details of pyroclastic flows. It also indicates that a complete quantitative analysis of the experimental observations would have little point.

Measurements of the position of the flow front, $s$, along the slope as a function of time, $t$, were made during most of the experiments. Data from the larger apparatus at slope angles of $15^{\circ}$ and $30^{\circ}$ are plotted in Fig. 8. In the logarithmic plot of position against time the points fall almost on a straight line. So, it is seen that for a particular flow rate and slope angle the front propagates quite reasonably as a power of the time, i.e. $s=A t^{B}$. The mean value of $B$ for all the experiments was 0.62 and the departure from this value was generally less than 0.05 . Increasing the input rate but retaining the slope angle increased the value of $A$, indicating that higher input rates caused the flow to move more rapidly. Increasing the slope angle without altering the input rate caused the flow also to move more rapidly, at least over the 3 slope angles used. It is interesting to recall that in our experiments with simple gravity currents, $B \approx 1$, which indicates that simple gravity currents flow more rapidly.

Only three experiments were performed with MEG compositions 2 and 3 of Fig. 1 because the results were so predictably similar to those with 

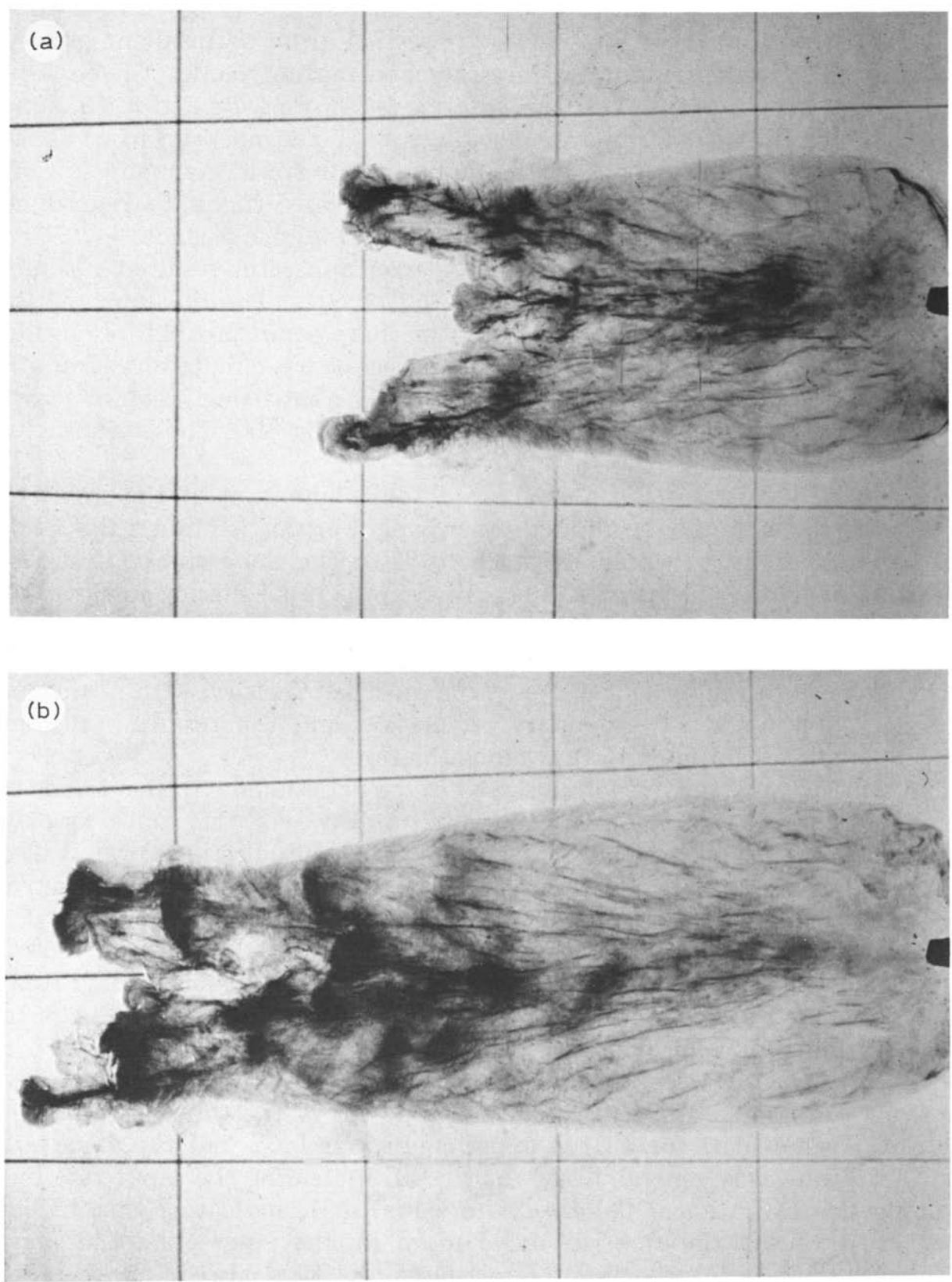

Fig. 7. Plans of a gravity current with a buoyant cloud in the larger apparatus with nozzle $b, Q=4.2 \mathrm{~cm}^{3} \mathrm{~s}^{-1}$. (a) $40 \mathrm{~s}$ after release; (b) $70 \mathrm{~s}$ after release. Note the very broad current (in contrast to those depicted in Fig. 4) due to the secondary circulation in the nozzle and the two branches of the current in (a) which have almost merged in (b). 


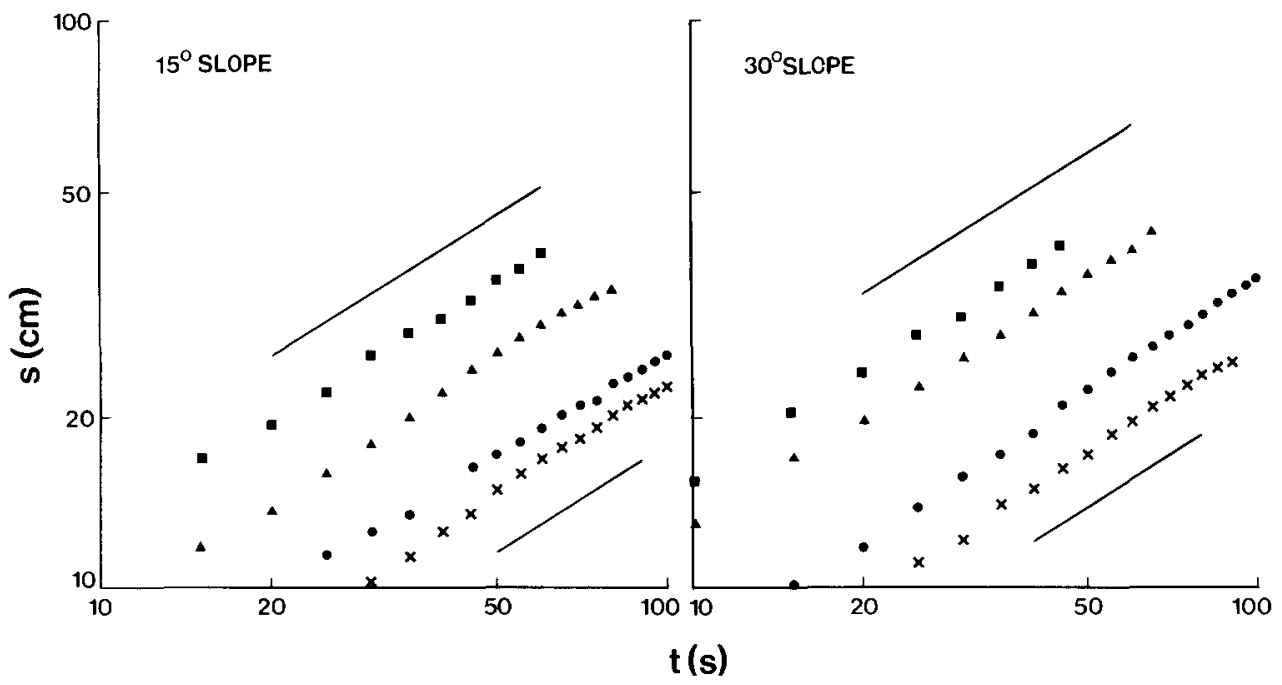

Fig. 8. The position of the front of the current as a function of time in the larger apparatus (with nozzle $d$ ) for a slope of (a) $15^{\circ}$ and (b) $30^{\circ} . \times Q=0.35 \mathrm{~cm}^{3} \mathrm{~s}^{-1} ; \bullet Q Q=0.50$ $\mathrm{cm}^{3} \mathrm{~s}^{-1} ; \Delta Q=1.1 \mathrm{~cm}^{3} \mathrm{~s}^{-1}$; and $-Q=2.0 \mathrm{~cm}^{3} \mathrm{~s}^{-1}$. The two inclined lines on each graph represent $s \propto t^{0.62}$. Note that each curve in (a) appears above its counterpart in (b), which indicates that flows along a $15^{\circ}$ slope travel more slowly than along a $30^{\circ}$ slope.

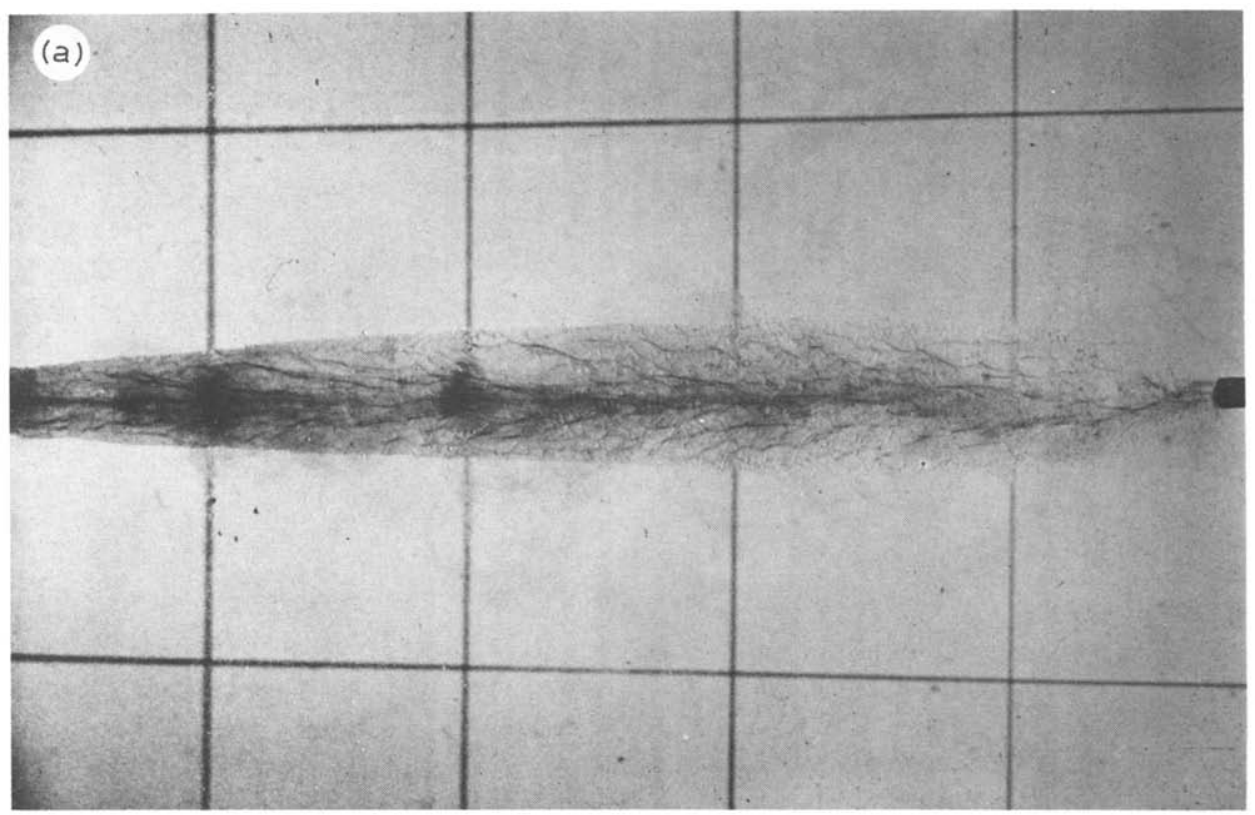

Fig. 9. Plan of a gravity current with a buoyant cloud after the input has ceased. The flow was maintained for $100 \mathrm{~s}$. These photos were taken in the larger apparatus (with nozzle $d$ ), $Q=0.5 \mathrm{~cm}^{3} \mathrm{~s}^{-1}$, at (a) $20 \mathrm{~s}$, (b) $40 \mathrm{~s}$ and (c) $70 \mathrm{~s}$ after the input was turned off. Note the gradual contraction of the current and the streakiness evident in (a) and (b). 

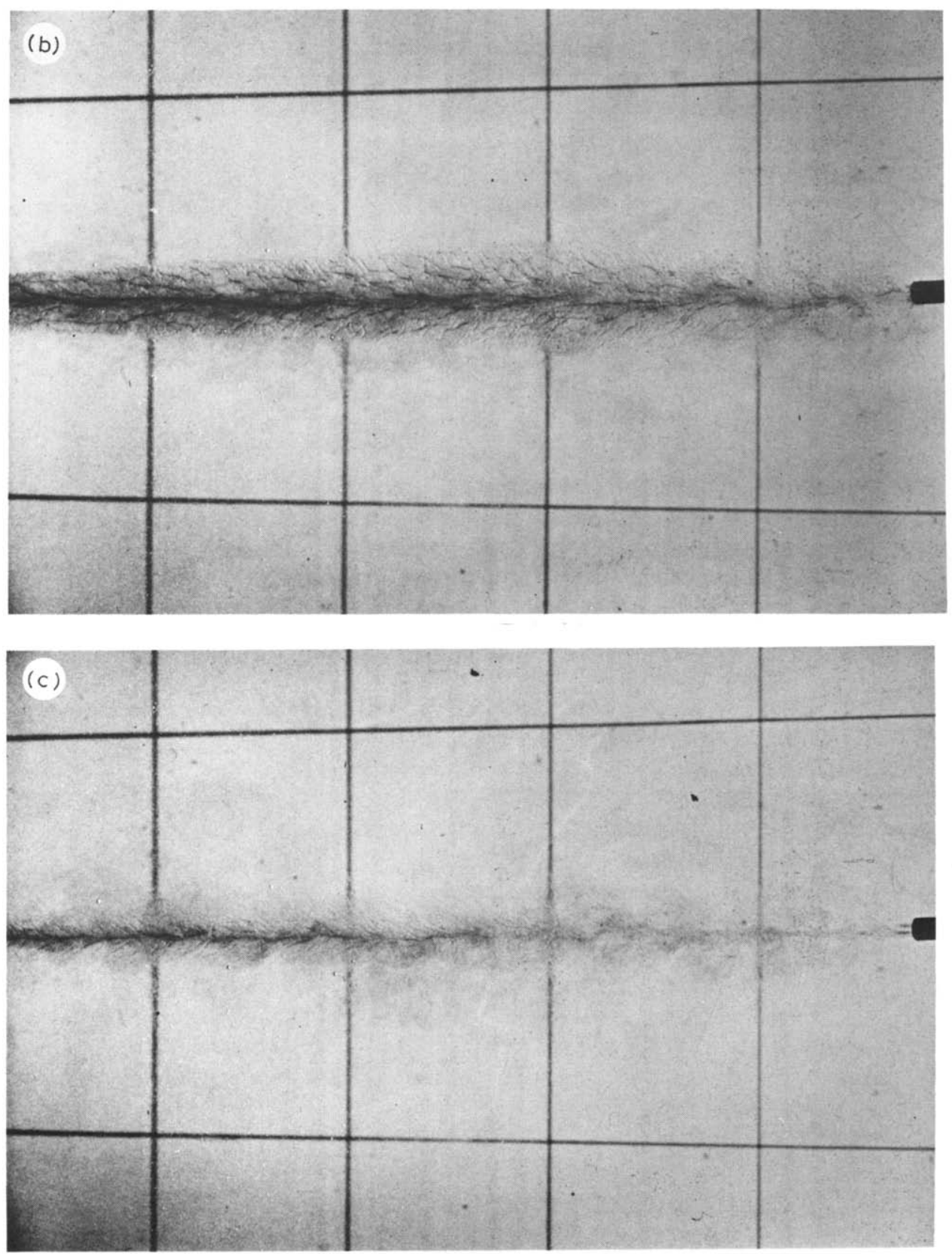

Fig. 9. b and c. For caption see p. 193.

composition 1 . The experiments with composition 2 showed less nonlinear mixing than those with composition 1 , and the MEG tended to remain attached as it flowed along the slope. The experiment with composition 3 flowed most rapidly along the slope and there was very little convective activity away from the slope. 
When the flow was turned off, the current relaxed in a rather interesting way, which was very much controlled by the strong convective motions in the environment. First, the current became progressively more confined (Fig. 9a,b,c) while at the same time the flow above the current moved back towards the nozzle. Turning off the supply to a simple gravity current w ould not have produced either of these effects.

\section{APPLICATIONS TO PYROCLASTIC FLOWS}

Any application of our experimental results needs first to recognise that there are major differences between the scale and physical characteristics of pyroclastic flows and these laboratory gravity currents. The experiments cannot replicate the important sedimentation processes and do not take into account the much larger density contrast between pyroclastic flows and their environment. In particular, it is likely that many pyroclastic flows are controlled by particle interactions in the dense underflow and that their motion is best described in terms of non-turbulent avalanches of cohesionless particles, either in a fluidised or non-fluidised condition (Sparks, 1976; Denlinger, 1986). On the other hand, mixing processes in the flow head will be highly nonlinear and the overlying dilute cloud will also have a density comparable with the surrounding atmosphere where buoyancy effects can become significant.

Figure 10 shows calculations of the density of mixtures of hot ash and cold air with a temperature of $0^{\circ} \mathrm{C}$ and density of $1.25 \mathrm{~kg} \mathrm{~m}^{-3}$. Curves are shown for ash temperatures from $0{ }^{\circ} \mathrm{C}$ to $1000{ }^{\circ} \mathrm{C}$ and illustrate the strongly nonlinear character of these mixtures. For dilute mixtures where the ash temperature exceeds about $300{ }^{\circ} \mathrm{C}$ and low mass fractions of ash

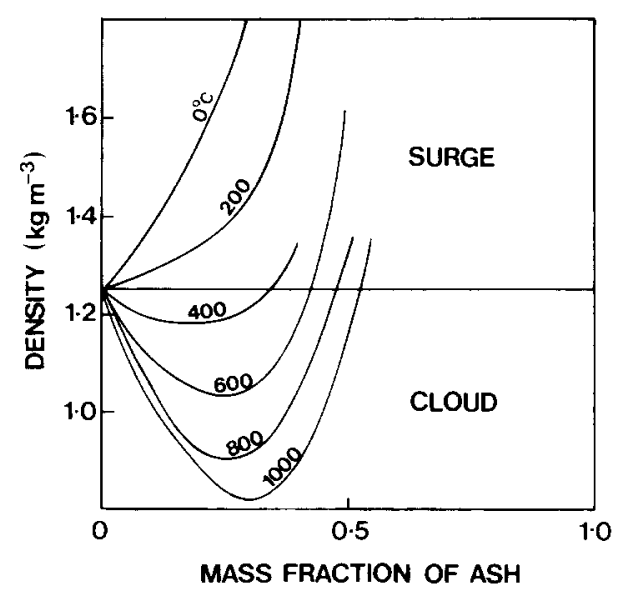

Fig. 10. Relationship between the density of mixtures of hot ash and cold air and the proportion of ash in the mixture. The air is assumed to have an initial temperature of $0^{\circ} \mathrm{C}$ and an initial density of $1.25 \mathrm{~kg} \mathrm{~m}^{-3}$. Curves are shown for different ash temperatures. 
(generally less than 0.5), the mixtures are buoyant. However, it is improbable that such dilutions can be achieved within the flow head itself, because of the large density contrast between air and ash. For example, a temperature of $1000{ }^{\circ} \mathrm{C}$ with a flow density of $1000 \mathrm{~kg} \mathrm{~m}^{-3}$ would have to mix with nearly one thousand times the volume of air to become buoyant. Such large volumetric proportions of incorporated air are implausible, so we conclude that mixing in the front of a dense flow will not directly cause the effects seen in the experiments.

The overlying ash cloud is in fact a more likely environment for the buoyancy effects to become important. The ash cloud is an environment where particle concentration and density are much lower than the pyroclastic flow itself. Moreover, the ash cloud density will depend on both the temperature and ash content and can be lighter than the overlying air if sufficiently dilute (Fig. 10). Dense portions of the ash cloud are thought to behave like dilute gravity currents to produce surge deposits (Fisher, 1979), whereas the buoyant portions produce ash-fall deposits (Sparks et al., 1973). Observations of pyroclastic flows indicate that the ash cloud can detach itself and move independently of the underlying avalanche, even if it comes to rest. The nonlinear mixing effects could thus become important in the behaviour of the ash cloud.

Detailed observations of the August 7th pyroclastic flow (Hoblitt, 1986) during the 1980 activity of Mount St. Helens, and of the 1951 pyroclastic flows of Mount Lamington in Papua New Guinea (Taylor, 1958), suggest dynamical behaviour similar to that observed in the experiments.

The August 7th flow moved down the flanks of Mount St. Helens along a well-defined valley containing gentle curves and then ran out onto a smooth plain with a much lower slope. Velocity data show that the flow went through three distinct cycles of acceleration and deceleration. Hoblitt (1986) attributes two of these cycles to changes in slope along the valley. However, one of the most marked cycles occurred where the flow was unconfined on the smooth gently sloping plain. This cycle was also accompanied by a distinctive change in appearance of the flow front. To quote Hoblitt (1986):

"The voluminous billowing, colloform clouds that marked the flow front ceased to advance and began to rise. Concurrently, the front became thin, wedge-shaped, digitate, and was followed by only small ash clouds. I suggest that these changes in velocity and appearance occurred when a pyroclastic surge derived from and preceding the pyroclastic flow was overtaken by the pyroclastic flow."

In the case of the March 5th, 1951 flow of Lamington, Taylor (1958) states:

"Occasionally the advance clouds of the nue ardentes would tend to become diffuse as if the gas supply were waning; then a few minutes later, 
new bursts of energy revitalised the ash cloud with highly-woven convolutions. The nuée was evidently a multiple event consisting of a series of successive overriding components."

Hoblitt (1986) proposed that the dilute ash cloud accelerated ahead of the basal avalanche near the break in slope. The avalanche may have slowed down on the shallow plain, allowing the ash cloud to move ahead as a dilute density current. Hoblitt attributes the deceleration of the dilute ash-cloud event to the onset of buoyancy causing the cloud to stop and rise. The behaviour of the ash-cloud event closely resembles the phenomena observed in our experiments and we concur with Hoblitt's explanation.

\section{APPLICATIONS TO THE DEPOSITS}

The results of the experiments also allow some cautious speculation to be made about recent models of pyroclastic flow deposition. Sparks et al. (1973) proposed a tripartite division of deposits produced by a "typical" pyroclastic flow. The lowest unit, layer 1 , is typically a stratified, crossbedded deposit with moderate sorting. This layer has been attributed both to the passage of a turbulent, relatively low-concentration, surge cloud which segregates from the advances ahead of the main body of the pyroclastic flow and to segregation of heavy material by fluidisation within the flow head (Wilson, 1980; Walker et al., 1981). Layer 2 is the main deposit from the flow and is characterised by poor sorting, a massive structure and sometimes by reverse grading of pumice blocks, normal grading of lithics and a tendency to fill in pre-existing depressions in the topography. Overlying layer 2 there is a widespread, fine ash fall deposit (layer 3 ) laid down by the upper convecting clouds of elutriated ash.

In the case of the Mount St. Helens flow described by Hoblitt (1986), the acceleration of the surge cloud ahead of the dense avalanche part of the flow would be expected to deposit a thin layer of surge deposits which would then be buried by the dense flow. Thus thin cross-bedded layer 1 deposits would underlie the main layer 2 deposit. It will be interesting to see if these expectations are realised when the August flow deposits are eventually exposed.

In much larger and more violent pyroclastic flow deposits Wilson and Walker (1982) have described basal deposits to the Taupo ignimbrite which they interpret as forming by the en masse deposition of material jetted out of the front of the main flow. They suggested that the jetting of the flow head is due to expansion of the gases ingested by the flow head. The experiments suggest an alternative interpretation of the jetted deposits. Discrete jets of flow material may be able to move ahead of the main flow head because of the pulsatory movement of the flow head due to air ingestion. Entrainment of air into the head and shedding of convective plumes could cause deceleration of the flow front and allow dense material to move momentarily ahead.

A (possible) interpretation for the origin of the jetted deposits, based on 
our experimental observations, would be that they represent pulses of the main flow which temporarily accelerate ahead of the fluidised flow head. The jetting, however, is not due to the expansion of air, but instead is an intrinsic oscillation of the flow imposed by the nonlinear density mixing relationship with the ambient fluid, i.e. the atmosphere.

\section{ACKNOWLEDGEMENTS}

This research was supported by the BP Venture Research Unit, the NERC, the NSF via Grant NSF 8306384 to SNC and H. Sigurdsson and a grant from the Royal Society/Australian Academy of Science Exchange programme to JST. We are grateful to Ross Wylde-Browne for his assistance with the reproduction of the photographs and to Rick Hoblitt for correspondence and discussions on the Mt. St. Helens flow, as well as for useful comments on the paper and valuable information concerning a cyst. Useful discussions with Colin Wilson are also acknowledged. Helpful reviews on earlier drafts were sent us by A. Freundt, R. Hoblitt, R.C. Kerr, A.R. McBirney, C.J.N. Wilson and M.G. Worster.

\section{REFERENCES}

Britter, R.E. and Linden, P.F., 1980. The motion of the front of a gravity current travelling down an incline. J. Fluid Mech., 99: 531-543.

Denlinger, R.P., 1986. A model for generation of ash clouds by pyroclastic flows, with application to the 1980 eruptions at Mount St. Helens. J. Geophys. Res. (sub judice).

Fisher, R.V., 1979. Models for pyroclastic surges and pyroclastic flows. J. Volcanol. Geotherm. Res., 6: 305-318.

Hoblitt, R.P., 1986. Observations of the eruptions of July 22 and August 7, 1980 at Mount St. Helens, Washington. U.S. Geol. Surv., Spec. Pap., 1335: 1-44.

Lighthill, M.J., 1979. Waves in Fluids. Cambridge University Press, Cambridge, 504 pp.

Prandtl, L., 1954. Essentials of Fluid Dynamics. Blackie and Son, London, $452 \mathrm{pp}$.

Simpson, J.E., 1982. Gravity currents in the laboratory, atmosphere and ocean. Annu. Rev. Fluid Mech., 14: 213-234.

Sparks, R.S.J., 1976. Grain size variations in ignimbrites and implications for the transport of pyroclastic flows. Sedimentology, 23: 147-188.

Sparks, R.S.J., Self, S. and Walker, G.P.L., 1973. Products of ignimbrite eruptions. Geology, $1: 115-118$.

Taylor, G.A.M., 1958. The 1951 eruption of Mount Lamington, Papua. Aust, Bur. Miner. Resour., Bull., 38, 129 pp.

Turner, J.S., 1966. Jets and plumes with negative or reversing buoyancy. J. Fluid Mech., $26: 779-792$.

Turner, J.S. and Gustafson, L.B., 1978. The flow of hot saline solutions from vents on the sea floor - some implications for exhalative massive sulfide and other ore deposits. Econ. Geol., 13: 1082-1100.

Turner, J.S. and Yang, I.K., 1963. Turbulent mixing at the top of stratocumulus clouds. J. Fluid Mech., 17: 212-224.

Walker, G.P.L., Self, S. and Froggatt, P.C., 1981. The ground layer of the Taupo ignimbrite: a striking example of sedimentation from a pyroclastic flow. J. Volcanol. Geotherm. Res., 10: 1-11. 
Wilson, C.J.N., 1980. The role of fluidization in the emplacement of pyroclastic flows: an experimental approach. J. Volcanol. Geotherm. Res., 8: 231-249.

Wilson, C.J.N., 1984. The role of fluidization in the emplacement of pyroclastic flows II: experimental results and their interpretation. J. Volcanol, Geotherm. Res., 20: 55-84.

Wilson, C.J.N. and Walker, G.P.L., 1982. Ignimbrite depositional facies; the anatomy of pyroclastic flow. J. Geol. Soc. London, 139: 581-592.

\section{NOTE ADDED IN PROOF:}

Further discussion of the motion of simple gravity currents appears in: Alavian, V., 1986. Behaviour of density currents on an incline. J. Hydraul. Eng., ASCE, 112: 27-42. 